\title{
Ulnar Artery
}

National Cancer Institute

\section{Source}

National Cancer Institute. Ulnar Artery. NCI Thesaurus. Code C12839.

A terminal branch of the brachial artery arising just below the elbow that runs along the ulna into the wrist with numerous branches supplying the forearm, wrist and hand. 